\title{
TWIST1 associates with NF- $\kappa$ B subunit RELA via carboxyl-terminal WR domain to promote cell autonomous invasion through IL8 production
}

Shan Li ${ }^{1,4}$, Stephen E Kendall ${ }^{1,6}$, Raquel Raices ${ }^{1,10}$, James Finlay ${ }^{1,4}$, Maricela Covarrubias ${ }^{1,7}$, Zheng Liư ${ }^{3}$, Gina Lowe ${ }^{1}$, Yu-Huey Lin ${ }^{1,5}$, Yuan Han Teh ${ }^{1,5}$, Victoria Leigh ${ }^{1,8}$, Simi Dhillon ${ }^{1,9}$, Steven Flanagan ${ }^{1}$, Karen S Aboody ${ }^{1,2}$ and Carlotta A Glackin ${ }^{1 *}$

\begin{abstract}
Background: Metastasis is the primary cause of death for cancer patients. TWIST1, an evolutionarily conserved basic helix-loop-helix (bHLH) transcription factor, is a strong promoter of metastatic spread and its expression is elevated in many advanced human carcinomas. However, the molecular events triggered by TWIST1 to motivate dissemination of cancer cells are largely unknown.

Results: Here we show that TWIST1 induces the production of interleukin 8 (IL8), which activates matrix metalloproteinases and promotes invasion of breast epithelial and cancer cells. In this novel mechanism, TWIST1mediated IL8 transcription is induced through the TWIST1 carboxy-terminal WR (Trp-Arg) domain instead of the classic DNA binding bHLH domain. Co-immunoprecipitation analyses revealed that the WR domain mediates the formation of a protein complex comprised of TWIST1 and the nuclear factor-kappaB (NF- $\kappa$ B) subunit RELA (p65/NF$\kappa \mathrm{B} 3)$, which synergistically activates the transcriptional activity of NF- $\kappa \mathrm{B}$. This activation leads to increased DNA binding affinity of RELA to the IL8 promoter and thus induces the expression of the cytokine. Blockage of IL8 signaling by IL8 neutralizing antibodies or receptor inhibition reduced the invasiveness of both breast epithelial and cancer cells, indicating that TWIST1 induces autonomous cell invasion by establishing an IL8 antocrine loop.

Conclusions: Our data demonstrate that the TWIST1 WR domain plays a critical role in TWIST1-induced IL8 expression through interactions with and activation of NF- $\kappa$ B. The produced IL8 signals through an autocrine loop and promotes extracellular matrix degradation to enable cell invasion across the basement membrane.
\end{abstract}

Keywords: TWIST1, WR domain, RELA, NF-KB, IL8

\section{Background}

While treatment of the primary breast tumor is often well managed with surgery and radiation, metastatic spread to the brain, bones, liver and lungs frequently places women in an incurable state of disease [1]. The basic helix-loophelix (bHLH) transcription factor TWIST1 was previously demonstrated to be a potent promoter of cancer cell dissemination into circulation and metastasis [2-7], providing an ideal target for investigation and a promising therapeutic target for intervention.

\footnotetext{
* Correspondence: cglackin@coh.org

'Division of Neurosciences, Beckman Research Institute of the City of Hope, Duarte, CA 91010, USA

Full list of author information is available at the end of the article
}

Based on its role in mesodermal development during mammalian embryogenesis [8,9], TWIST1 is proposed to induce an embryonic event termed epithelialmesenchymal transition (EMT) in tumor cells to promote the expression of mesenchymal junction proteins in epithelial cells and reduce intercellular junctions in the meantime $[2,10,11]$. Induction of EMT enables epithelial cells to acquire the properties of mesenchymal lineages, including enhanced mobility and invasiveness that are tightly correlated with cancer metastasis $[12,13]$. Additionally, TWIST1 was shown to regulate the expression of AKT2 [14] and miRNA-10b [15], which are subsequently involved in the migratory and invasive properties of TWIST1-overexpressing cells. Eckert et al. 
recently reported that TWIST1 up-regulates the expression of platelet derived growth factor receptor, which in turn promotes the formation of invadopodia and matrix degradation [16], presenting the first evidence that TWIST1 causes extracellular matrix (ECM) remodeling. However, the mechanisms by which TWIST1 actively promote cell invasion are still largely unstudied.

TWIST1 is a class II member of the bHLH super family [17]. It homo- or heterodimerizes with class I HLH family members, such as E proteins (E12/E47), through the HLH domain, and binds DNA that contains the E-box sequence (CANNTG) via the basic domain to regulate gene expression [18]. Loss of function mutations in the bHLH domain in one allele of the TWIST1 gene cause Saethre-Chotzen Syndrome (SCS) in humans, an autosomal dominant craniofacial disease caused by gene haploinsufficiency [18-20], denoting the functional importance of the TWIST1 bHLH domain. TWIST1 also contains a highly conserved carboxy-terminus (C-terminus), the WR (TrpArg) domain (comprising the last 20 amino acid residues of TWIST1), which shares $100 \%$ sequence homology among jellyfish, Xenopus, mice and humans [17]. This region was shown to mediate the association between TWIST1 and Runx2, a zinc-finger protein, and prevent Runx2 from inducing premature osteoblast differentiation during bone development in mice [21]. However, whether the highly conserved WR domain plays any roles in TWIST1-induced cancer metastasis is an open question.

Here we describe a unique property of the TWIST1 WR domain in mediating IL8 production and breast cancer cell invasion. Using Gene Set Enrichment Analysis (GSEA) of genetic profiles and cytokine array analyses, we found that IL8 was specifically up-regulated by TWIST1 overexpression in the human breast epithelial cell line MCF10A as well as other breast cancer cell lines. We also discovered that TWIST1 activates the IL8 promoter, but, surprisingly, in a manner that is independent of its canonical DNA binding bHLH domain. In contrast, TWIST1induced IL8 promoter activation is dependent on the Cterminal WR domain, through which TWIST1 interacts with the NF- $\kappa$ B subunit RELA. This physical association of TWIST1 and RELA activated and synergized the transcriptional activity of NF- $\kappa \mathrm{B}$ and increased the binding affinity of RELA to DNA, which in turn stimulated IL8 expression. Finally, we demonstrate that the IL8 autocrine pathway in breast epithelial and cancer cells increases matrix metalloproteinase (MMP) production and enables autonomous invasion of the cells.

\section{Results}

\section{TWIST1 induces IL8 cytokine production}

To elucidate the molecular function of TWIST1 in human breast epithelial cells, we compared the gene expression profiles of a TWIST1 over-expressing mammary epithelial cell line (MCF10ATw) and the parental line from which it was derived (MCF10A). We analyzed these data by GSEA (2.07) using the C2 canonical pathway gene sets [22] on paired independent experiments performed in triplicate using these cell lines. The returned gene set permutation test showed a significant difference in the BioCarta_Cytokine_Pathway between MCF10A and MCF10ATw cells at a false discovery rate of 0.012 (Additional file 1, Figure S1A and $D)$. The gene set included the pro-inflammatory cytokine interleukin 1 alpha (IL1 $\alpha$ ) and the leukocyte chemokine IL8 as two significant contributors to the BioCarta_Cytokine_Pathway enrichment, with respective ranks of 3 and 11 as determined by signal-to-noise metric among all genes on the gene array, and in concordance with TWIST1 expression (Additional file 1, Figure S1B, D).

To verify the up-regulation of these genes, we performed a cytokine array blot with conditioned media collected from MCF10A or MCF10ATw cell cultures. In this experiment, IL8, along with growth related oncogene (GRO) and angiogenin (ANG), showed the most pronounced up-regulation in MCF10ATw cells; however, secreted IL1 $\alpha$ was not detected (Figure 1A, Additional file 2, Table S1). Quantification of IL8 revealed 34-fold greater mRNA expression and 3-fold greater secretion of IL8 protein into culture media of MCF10ATw relative to MCF10A cells (Additional file 1, Figure S1C). To test if IL8 was selectively up-regulated in the MCF10ATw stable cell line, we transiently transduced MCF10A parental cells with adenoviruses that expressed TWIST1 at serial dilutions and observed that IL8 transcripts were up-regulated in a dose dependent manner that correlated with the levels of TWIST1 expressed (Figure 1B). Since IL8 was up-regulated at both the mRNA and protein levels, indicating that IL8 is a downstream target of TWIST1, we, therefore, focused on elucidating the regulatory pathway of IL8.

To evaluate the induction of IL 8 by TWIST1 under pathological conditions, we expressed TWIST1 in the SKBR3 (epidermal growth factor receptor 2 positive, ERBB2/HER2+) and MCF7 (estrogen receptor positive, ER+) cell lines, which represent two different subtypes of breast cancer, and observed respective 20 -fold and 4-fold increases in IL8 transcript levels (Figure 1C). The difference in IL8 transcript levels between these two cell lines may be due to the influence of ERBB2 expression on NF$\kappa \mathrm{B}$ transcriptional activity [23]. In addition, short hairpin RNA (shRNA)-mediated knock-down (KD) of endogenous TWIST1 reduced the expression of IL8 mRNA in BT549 cells (Figure 1D), a triple-negative breast cancer cell line (progesterone receptor negative (PR-), ER- and HER2-) that expresses high endogenous levels of both TWIST1 and IL8. This reduction in IL8 expression 
A

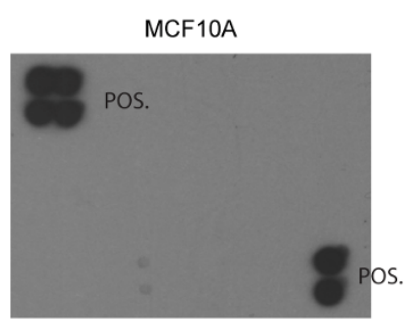

C

SKBR3

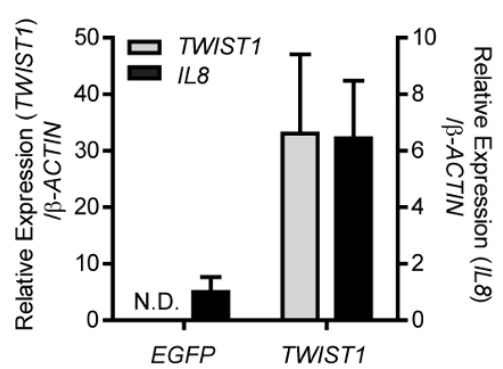

B

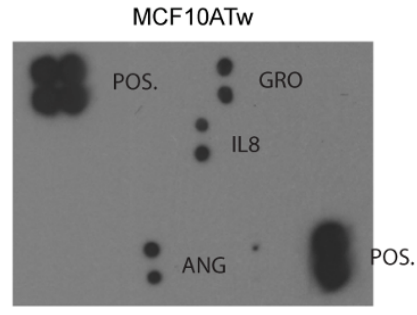

MCF7

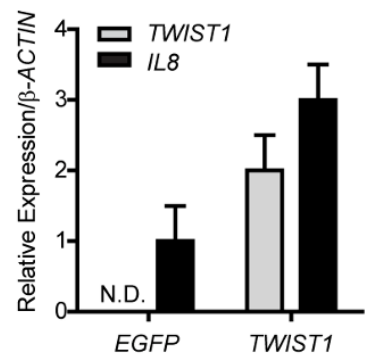

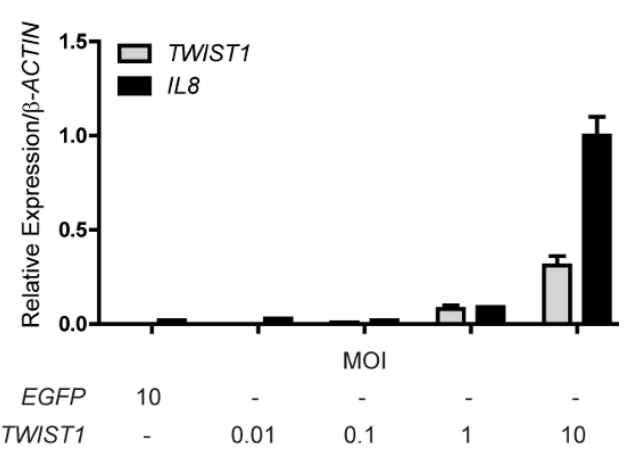

BT549

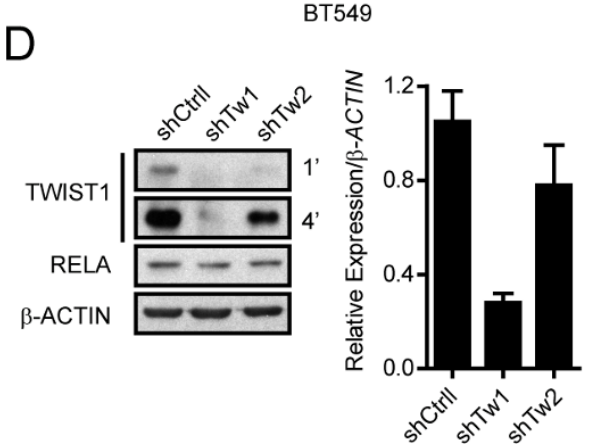

Figure 1 TWIST1 induces IL8 Production. (A) Cytokine array blotted with conditioned media collected from MCF10A or MCF10ATw cell cultures. Cytokines detected in MCF10ATw conditioned medium are shaded in Additional File 2, Table S1. POS, positive controls. (B) Relative mRNA levels of TWIST1 and IL8 normalized to $\beta$-ACTIN See Methods) in MCF10A cells 48 h post-transduction with adenoviruses that express TWIST1 (Ad.TWIST) at a serial multiplicity of infection (MOI). Cells transduced with Ad.EGFP (enhanced green fluorescent protein) at an MOI of 10 were used as controls. (C) Relative mRNA levels of TWIST1 and IL8 normalized to $\beta$-ACTIN as in (B) in SKBR3 and MCF7 cells 48 h posttransduction with Ad.TWIST as compared to Ad.EGFP (control). MOI = 5. (D) Relative mRNA levels of IL8, normalized as in (B), in BT549 cells with TWIST1 KD (right). Cells were transduced with lentiviruses that expressed a non-targeting shRNA (shCtrl) or shRNAs that targeted TWIST1 (shTw1, shTw2). Western blot (left) shows the levels of TWIST1 under these conditions. One and four minute exposures of the blot are shown. RELA is shown as a KD control. The data are from single representative quantification or images of at least three independent experiments.

correlated with the amount of TWIST1 protein knocked down (Figure 1D). Taken together, these data show that TWIST1 regulates and maintains IL8 expression in breast epithelial and cancer cells.

\section{TWIST1-induced IL8 transcription is mediated by the TWIST1 WR domain}

To investigate whether TWIST1 activates IL8 transcription, we cloned the IL8 minimal promoter [24], which contains a putative TWIST1 binding site (an E-box sequence, CAGTTG) and a consensus $\kappa \mathrm{B}$ response element, into a luciferase reporter construct (Figure 2A). SKBR3 and MCF7 cells transfected with this IL8 promoter construct displayed a consistent increase in luciferase activities when co-transfected with TWIST1, indicating transcriptional activation of IL8 (Figure 2B). Correspondingly, in BT549 cells, TWIST1 KD resulted in a decrease in IL8 promoter activity, and this activity was rescued upon exogenous TWIST1 expression (Figure 2C).
To further clarify whether TWIST1 directly binds and activates the IL8 promoter, we transfected SKBR3 and MCF7 cells with an IL8 promoter construct that was mutated at the putative TWIST1 binding E-box (Figure 2A, $\triangle \mathrm{E}$-box, CA:GT). In this experiment, TWIST1 failed to stimulate luciferase transcription (Additional file 3, Figure $\mathrm{S} 3 \mathrm{~A}$ ), indicating that integrity of the E-box sequence is required for IL8 promoter activation. However, we were concerned that these mutations may affect the binding of $\mathrm{C} / \mathrm{EBP}$, a known regulator of IL8 because the E-box sequence heavily overlaps with the C/EBP binding site [25]. Therefore, we generated two DNA binding deficient TWIST1 mutants by introducing the S144R/K145E and R118C mutations (Figure 2B and S2B). These naturally occurring mutations found in SCS patients abolish the DNA binding ability of TWIST1/E12 heterodimers without affecting its subcellular localization [18]. Surprisingly, both the S144R/K145E (Figure 2B) and R118C (Additional file 3, Figure S2B) TWIST1 mutants stimulated the IL8 promoter 


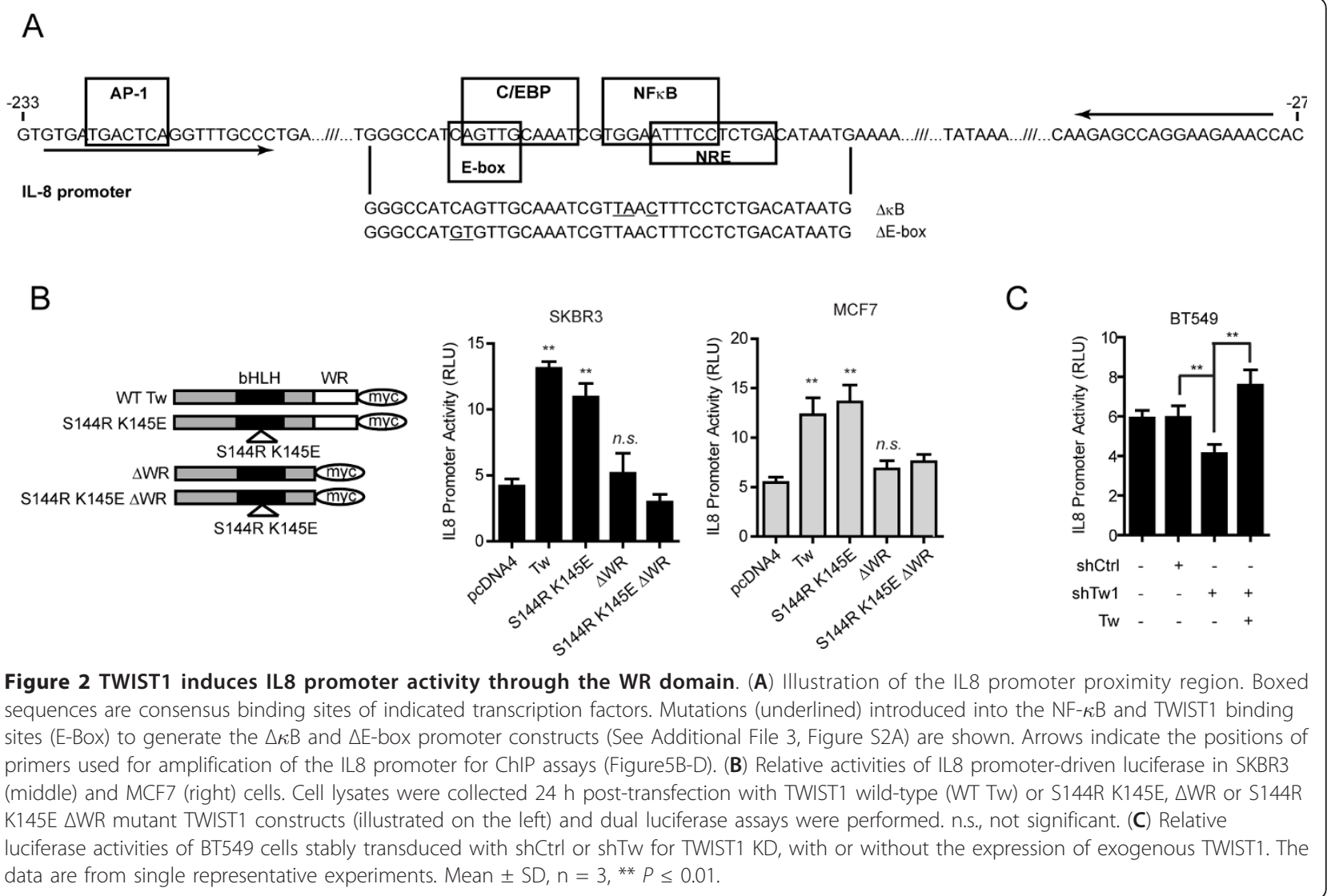

at similar levels as wild type (WT) TWIST1 in SKBR3 and MCF7 cells (Figure 2B and Additional file 3, Figure S2B). To further validate that the DNA binding ability of TWIST1 is not required for IL8 promoter activation, we completely removed the bHLH domain of TWIST1 $(\triangle \mathrm{bHLH})$ and still observed IL8 promoter activity induced by this mutant comparable to that of wild type TWIST1 in MCF7 cells (Additional file 3, Figure S2B). More importantly, when we performed chromatin immunoprecipitation (ChIP) assays with solubilized chromatin collected from MCF10A cells transfected with S144R/K145E DNA-binding deficient TWIST1 mutant, we did not detect any statistically significant enrichment of mutant TWIST1 capable of activating IL8 expression on the IL8 promoter (See later results, demonstrating that the activation of IL8 promoter is independent of DNA binding activity of TWIST1.

To better understand which region of the TWIST1 protein is responsible for IL8 promoter activation, we decided to remove the last 20 amino acids at the C-terminal end of TWIST1, which comprise its highly conserved WR domain $(\triangle \mathrm{WR})$, and transfected this $\triangle \mathrm{WR}$ mutant protein into SKBR3 and MCF7 cells. Intriguingly, unlike the DNA binding deficient TWIST1 mutants, the $\Delta$ WR truncation mutant protein completely lost its ability to activate the IL8 promoter. Furthermore, combining the
S144R/K145E mutations with the WR deletion showed similar activation of the IL8 promoter as compared to $\triangle W R$ alone (Figure 2B), illustrating that the WR domain is essential for TWIST1-induced IL8 expression.

\section{TWIST1-induced IL8 expression is mediated by RELA}

It was reported by Sosic et al. that TWIST1 and 2 regulate the transcriptional activity of NF- $\kappa \mathrm{B}$ in mice and specifically TWIST2 does so through its $\mathrm{C}$-terminal region, which contains a WR domain [26]. Given that NF- $\kappa \mathrm{B}$ is a central regulator of IL8 [24] and that the WR domain is highly conserved between TWIST1 and TWIST2, we hypothesized that NF- $\kappa \mathrm{B}$ is involved in TWIST1-mediated IL8 promoter activation. To address this hypothesis, we made use of a dominant negative (DN) form of $\mathrm{I} \kappa \mathrm{B} \alpha$ (S32A S36A super repressor, I $\kappa$ BSR) that constitutively suppresses the activation of NF- $\kappa \mathrm{B}$ [27], and found that TWIST1 could no longer activate the IL8 promoter when co-transfected with this suppressor in both SKBR3 and MCF7 cells (Figure 3A). To determine if this was due to the inference of $\mathrm{I} \kappa \mathrm{BSR}$ on the expression or activity of TWIST1, we examined the expression of TWIST1 in the nuclei of cells co-transfected with $\mathrm{I} \kappa \mathrm{BSR}$, and in fact found greater amounts of TWIST1 protein in the nuclear fractions of these cells than cells transfected with TWIST1 


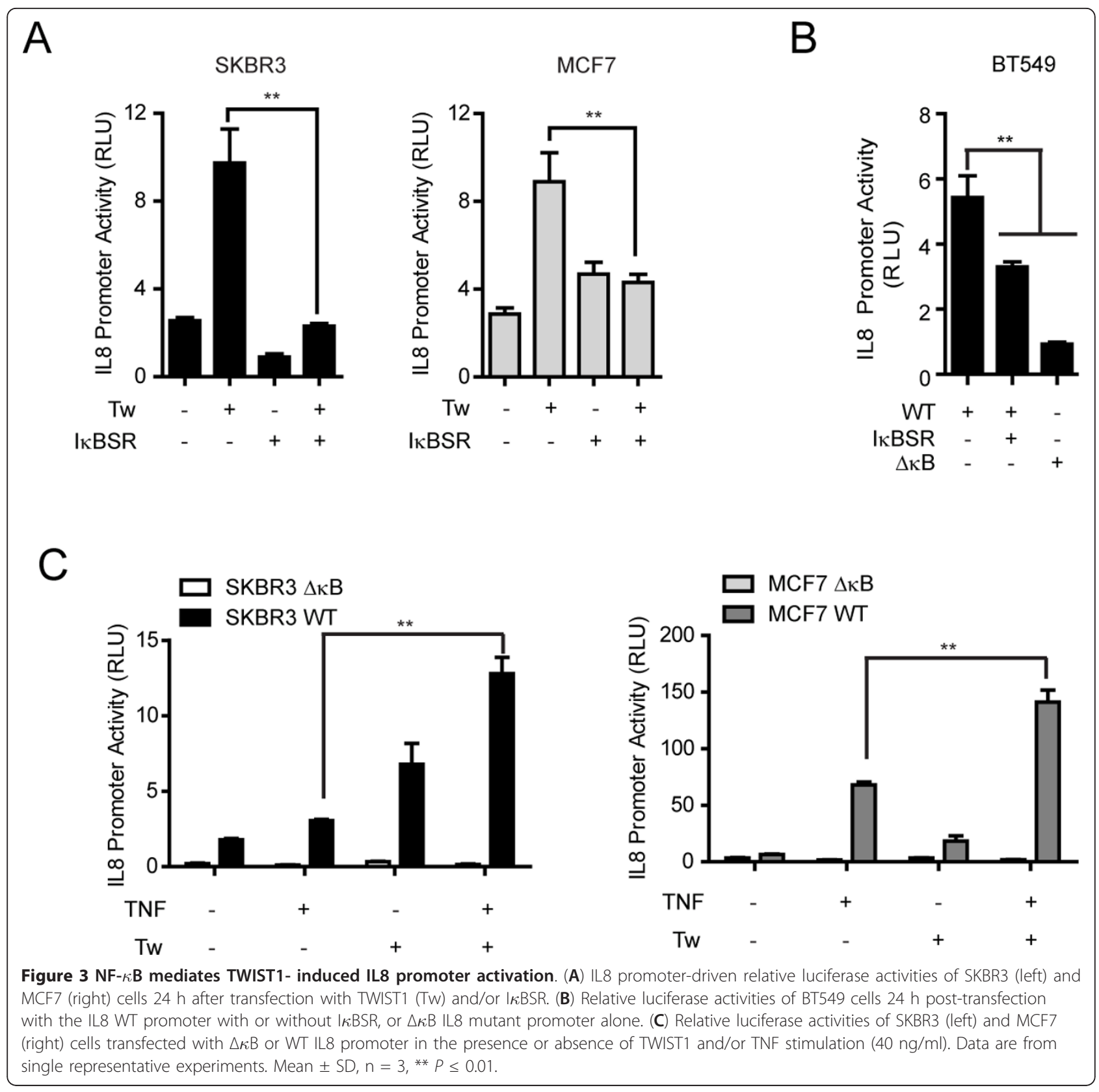

alone (Additional file 3, Figure S2C). Additionally, in BT549 cells, which express high endogenous levels of TWIST1, transfection of I $\kappa$ BSR showed attenuated IL8 promoter activity, which was completely abolished by mutations in the $\kappa \mathrm{B}$ consensus site that disrupts binding of NF- $\kappa \mathrm{B}$ to the IL8 promoter [25] (Figure 2A underlined $\Delta \kappa \mathrm{B}, 3 \mathrm{~B}$ ), indicating that $\mathrm{NF}-\kappa \mathrm{B}$ transcriptional activity is crucial in the expression regulation of IL8 in these cells.

To compare the role of TWIST1 and tumor necrosis factor alpha (TNF- $\alpha$ ), an activator of NF- $\kappa$ B, on IL8 promoter activation, we treated SKBR3 and MCF7 cells transfected with the IL8 promoter construct and DNA vector or TWIST1 with TNF- $\alpha$. Although the IL8 promoter was activated to greater levels by TNF- $\alpha$ alone than by TWIST1 transfection in both cell lines, the expression of TWIST1 synergized the effect of TNF- $\alpha$ on IL8 promoter activation in both cell lines. Moreover, mutations in the $\kappa \mathrm{B}$ consensus binding site eliminated this synergy, indicating that the synergistic effect of TWIST 1 and NF- $\kappa \mathrm{B}$ is dependent upon NF- $\kappa \mathrm{B} / \mathrm{DNA}$ binding (Figure $3 \mathrm{C}$ ). The above data also suggest that TWIST1 activates the transcriptional activity of NF- $\kappa \mathrm{B}$, possibly through a mechanism upstream of $\mathrm{I} \kappa \mathrm{B} \alpha$, different from the canonical TNF- $\alpha$ pathway. 
To further understand the mechanism by which the activation and synergy of NF- $\kappa$ B occurs, we focused on the NF- $\kappa \mathrm{B}$ subunit RELA, which is a conserved binding partner of TWIST1 $[26,28]$. To address whether RELA is the NF- $\kappa \mathrm{B}$ subunit that mediates TWIST1-induced IL8 expression, we performed shRNA-mediated KD of RELA in SKBR3 and MCF7 cells, and found that IL8 promoterdriven luciferase activity under TWIST1 over-expression was attenuated by RELA KD in both cell lines (Figure 4A). When we performed double KD of TWIST1 and RELA in BT549 cells, we observed a slight decrease of the IL8 promoter activity compared to TWIST1 KD (Additional file 3, Figure S2D), indicating that RELA alone is partially responsible for the basal expression of IL8. We also noticed that the KD of RELA in TWIST1 over-expressing cells was less efficient than in TWIST1null or low expressing cells, suggesting that TWIST1 expression may stabilize RELA protein when its expression is reduced without affecting its overall basal expression levels (Figure 4A and Additional file 3, Figure S2E). Additionally, forced expression of TWIST1 in HEK293 cells, which do not express detectable levels of TWIST1 or RELA (Figure 4C and Additional file 3, Figure S2F), failed to stimulate IL8 promoter activity; whereas transfection of these cells with RELA activated the IL8 promoter, which was further synergized by the co-transfection with TWIST1 (Figure 4B). Furthermore, mutations in the $\kappa \mathrm{B}$ consensus binding site abolished this synergistic effect between TWIST1 and RELA (Figure 4B), indicating that the association of NF- $\kappa$ B with DNA is necessary for IL8 transcriptional activation and synergism induction by TWIST1.

The TWIST1 WR domain was previously shown to mediate the interaction between TWIST1 and non-bHLH protein partners, such as Runx2 [21]. An association between recombinant murine TWIST1 and RELA was also previously reported [26]. Therefore, we speculated that the TWIST1 WR domain bridges an interaction between human TWIST1 and RELA. To address this, we performed RELA co-immunoprecipitation (co-IP) experiments using HEK293 cells transfected with WT or mutant TWIST1 using $\alpha$-RELA antibodies (Figure 4C). Consistent with earlier reports, WT human TWIST1 co-immunoprecipitated with RELA; and the TWIST1 bHLH mutant (S144R K145E) was also precipitated by $\alpha$-RELA antibodies in HEK293 cells transfected with the TWIST1 mutant and RELA. However, neither the $\triangle$ WR nor S144R K145E $\Delta$ WR TWIST1 mutant could be detected by $\alpha$-RELA antibodies in co-IP experiments when equal amounts of RELA were precipitated. Collectively, these results demonstrate that the TWIST1 WR domain is necessary for the association between RELA and TWIST1, and is crucial for transcriptional activation of TWIST1-induced IL8 expression.
To determine if this interaction between RELA and TWIST1 regulates the activity of NF- $\kappa \mathrm{B}$, we used a luciferase construct driven by an artificial promoter that contains three repeats of the $\kappa \mathrm{B}$ consensus sites $(3 \mathrm{x} \kappa \mathrm{B})$. In this experiment, both WT and S144R K145E TWIST1 stimulated the $\kappa \mathrm{B}$ consensus site in SKBR3 cells, but this stimulation was completely blocked by $\mathrm{I} \kappa \mathrm{BSR}$ expression, indicating that the activation was mediated by the endogenous NF- $\kappa \mathrm{B}$ (Figure 4D). In contrast, neither the $\Delta \mathrm{WR}$ nor S144R K145E $\Delta$ WR TWIST1 mutant could stimulate NF- $\kappa \mathrm{B}$ transcriptional activity in a similar manner in luciferase assays (Figure 4D). Furthermore, the increase in $\mathrm{NF}-\kappa \mathrm{B}$ transcriptional activity was dependent upon the amount of TWIST1 being expressed (Figure 4E), whereas $\triangle W R$ TWIST1 in any given amount failed to activate NF- $\kappa \mathrm{B}$ transcriptional activity in HEK293 cells transfected with the $3 \mathrm{x} \kappa \mathrm{B}$ luciferase construct (Figure $4 \mathrm{E}$ ). These results demonstrate that the TWIST1 WR domain, which mediates the association between TWIST1 and RELA, is essential for the activation of NF- $\kappa$ B transcriptional activity and synergy.

\section{TWIST1 increases the association of RELA with the IL8 promoter}

To confirm the physiologic relevance of the association between TWIST1 and RELA, we performed co-IP experiments with BT549 cells, which express endogenous TWIST1. Using $\alpha$-TWIST1 antibodies, we found that RELA was exclusively pulled down with TWIST1 in the nuclear but not the cytosolic fraction of BT549 cells (Figure 5A), suggesting that TWIST1 and RELA form a protein complex in the nuclear compartment.

Next, to understand if the TWIST1/RELA protein complex is associated with the IL8 promoter sequence and whether this protein/DNA association is essential for promoter activation, we performed ChIP assays using $\alpha$ TWIST1 antibodies with MCF10A cells transfected with WT TWIST1, S144R/K145E or $\Delta$ WR TWIST1 mutants (Figure 5B). We found that although the WT and the $\triangle$ WR TWIST1 mutant were associated with the IL8 promoter, the S144R/K145E DNA binding mutant is not presented at the same region, confirming that these point mutations indeed disrupt the DNA binding ability of the protein. More importantly, it demonstrates that the activation of RELA by TWIST1 can be achieved away from the IL8 promoter DNA and that the direct or indirect association of TWIST1 via RELA to the IL8 promoter is not required for IL8 transcription activation. In addition, we also observed that there is no difference in the enrichment of the IL8 promoter between WT TWIST1 and $\Delta W R$-expressing cells indicating that the interaction between TWIST1 and RELA does not appear to affect the ability of TWIST1 to become associated with the IL8 


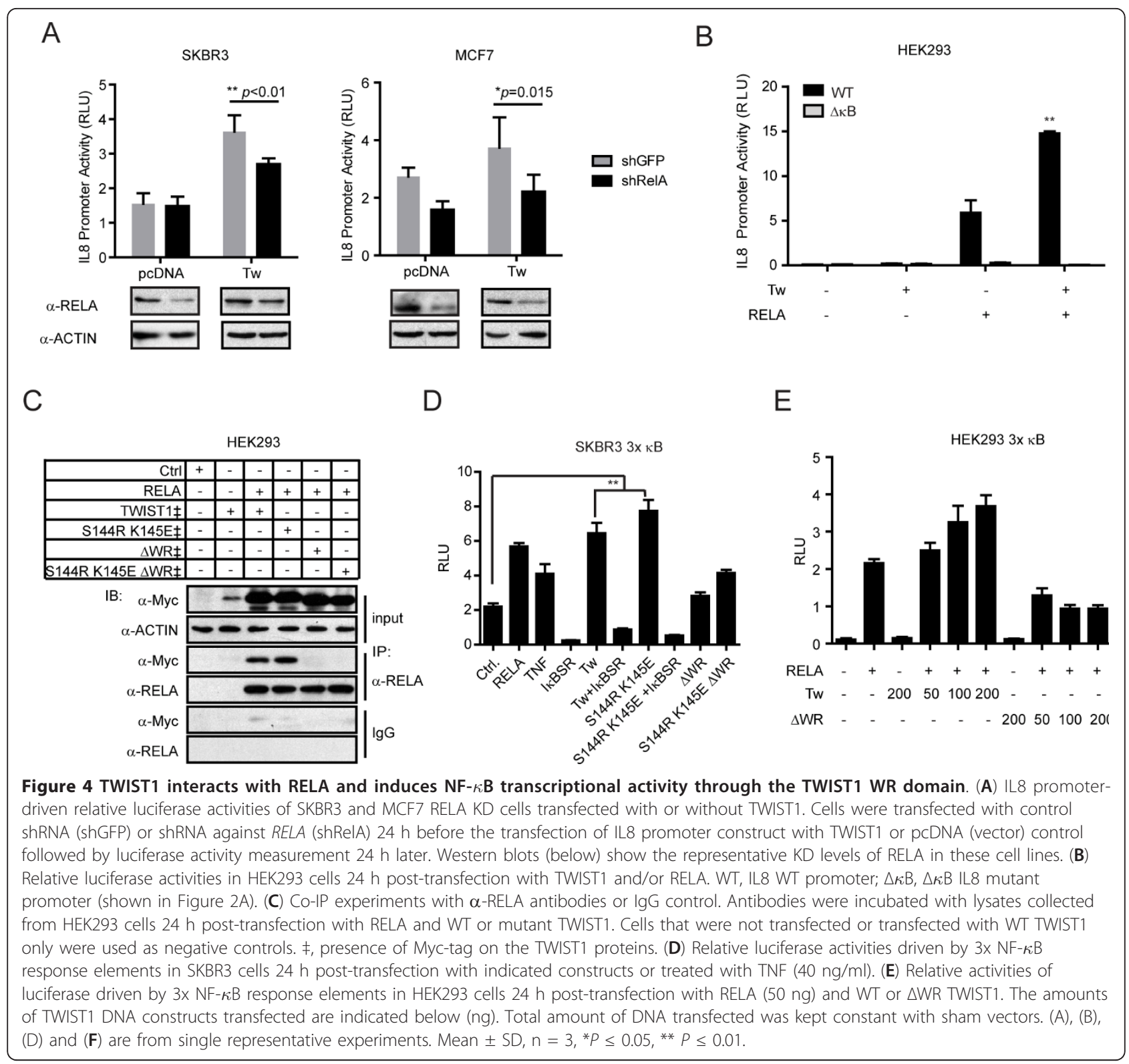

promoter, presumably through the E-box sequence (Figure 5B, Additional file 3, Figure S2G).

We further compared the association of RELA with the IL8 promoter between MCF10A and MCF10ATw cells and detected statistically enriched signals of RELA on the IL8 promoter in MCF10ATw relative to MCF10A cells (Figure 5C), which indicates that the binding affinity of RELA to the IL8 promoter is greatly enhanced in the presence of TWIST1. Reciprocally, the percentage of RELAassociated IL8 promoter was significantly reduced in BT549 cells when TWIST1 was KD (BT549.shTw1) compared to those transduced with non-targeting shRNA control (BT549.shCtrl) (Figure 5E, right). Together, these data demonstrate that TWIST1 increases the recruitment of RELA to the IL8 promoter.

\section{Elevated levels of IL8 enhance MMP activation and increase cellular invasive potential of breast epithelial cells}

Under physiological conditions, IL8 activates endothelial cells and neutrophils to produce and release MMPs to enhance their migration and invasion in order to facilitate angiogenesis and extravasation, respectively $[29,30]$. These observations suggest that IL8 produced by TWIST1-expressing breast cells may also alter their migratory and invasive potentials, features seen with 


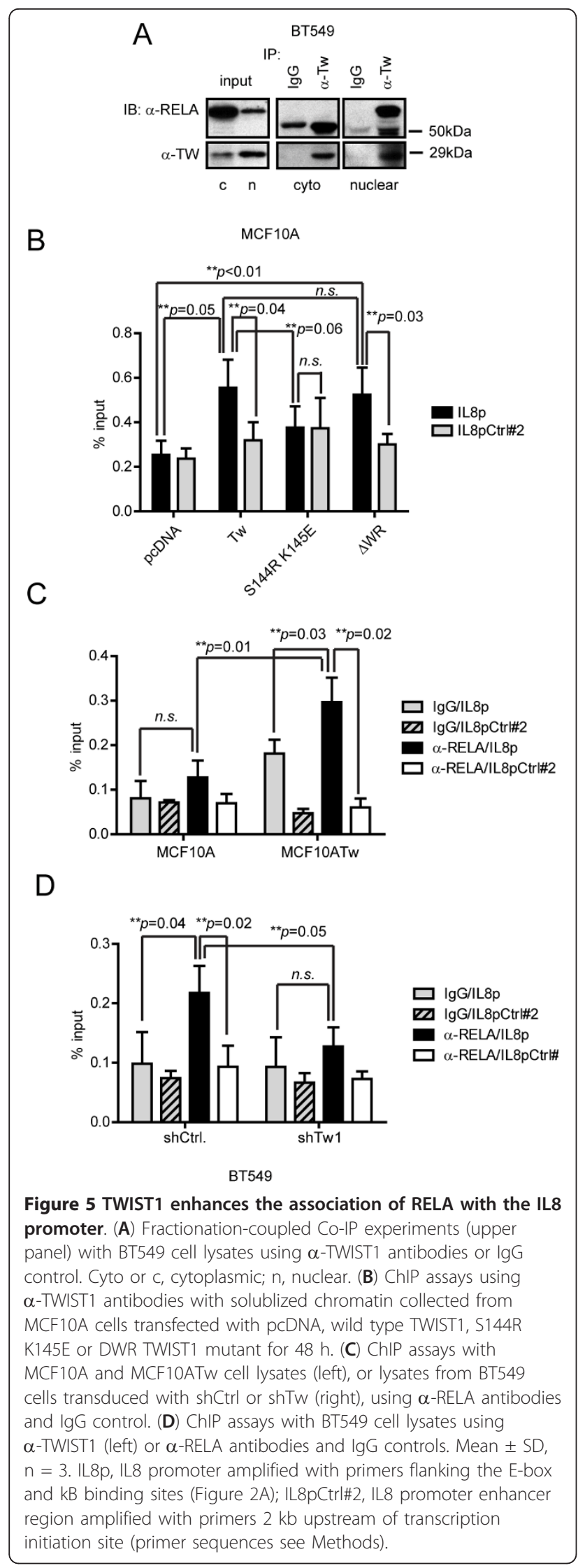

many invasive cancer cells. To examine this possibility, we compared MCF10A and MCF10ATw cells and found that expression of TWIST1 significantly increased the migratory and invasive potential of MCF10A cells in transwell assays towards serum-rich media (Figure 6A, C). When MCF10ATw cells were treated with IL8 neutralizing antibodies or inhibitors against the IL8 receptors (SB225002, a CXCR2 receptor inhibitor [31], Repertaxin, a CXCR1 and CXCR2 inhibitor [32]), the number of invasive cells was reduced by $50 \%$. Interestingly, no significant difference was seen in the number of migratory cells in response to IL8 signaling blockage (Figure 6A, C), indicating that TWIST1 mediates the production of IL8 to induce ECM degradation but not to enhance the cell's motility. To test whether blockage of the IL8 autocrine pathway affected cell division in the migration/invasion assays, we performed cell proliferation assays and found cell growth was not affected by the treatment of neutralizing antibodies or inhibitors (Figure 6B), verifying that the decrease in number of invaded cells was not a result of reduced proliferation.

Because IL8 autocrine signaling significantly altered the invasive properties of MCF10ATw cells, we analyzed the expression and activation levels of MMPs, which play important roles in ECM degradation. Using gelatin zymography, we found that the production and activation of MMP9 were greatly enhanced by TWIST1 overexpression in MCF10A cells. Addition of Repertaxin or SB2255002 to MCF10ATw cell cultures markedly reduced the expression and activation of both MMP2 and MMP9 to below detectable levels (Figure 6D). These results indicate that TWIST1 over-expression establishes an IL8 autocrine loop that regulates the production and activation of MMP2 and 9.

To investigate whether IL8 also mediates cellular invasiveness in cancer cells, we performed shRNA-mediated KD of IL8 in BT549 cells, and found a 40\% reduction in the number of invasive cells as compared to the nontargeting shRNA control. This reduction in the number of invasive cells as a result of IL8 KD was similar to that of the TWIST1 KD of BT549 cells in comparison to both non-targeting shRNA controls (Figure 6E). In addition, neither IL8 nor TWIST1 KD of BT549 cells displayed significant differences in their proliferation rates during the course of the invasion assay (Figure 6F). Collectively, these data demonstrate that TWIST1-induced IL8 production regulates the invasive properties of breast epithelial and cancer cells through an autocrine loop.

TWIST1 and IL 8 are selectively co-expressed in the basal subtype of human breast cancers

We compared the expression of TWIST1 and IL8 in multiple breast cancer cell lines, which revealed that both TWIST1 and IL8 are expressed in the basal but not in the 


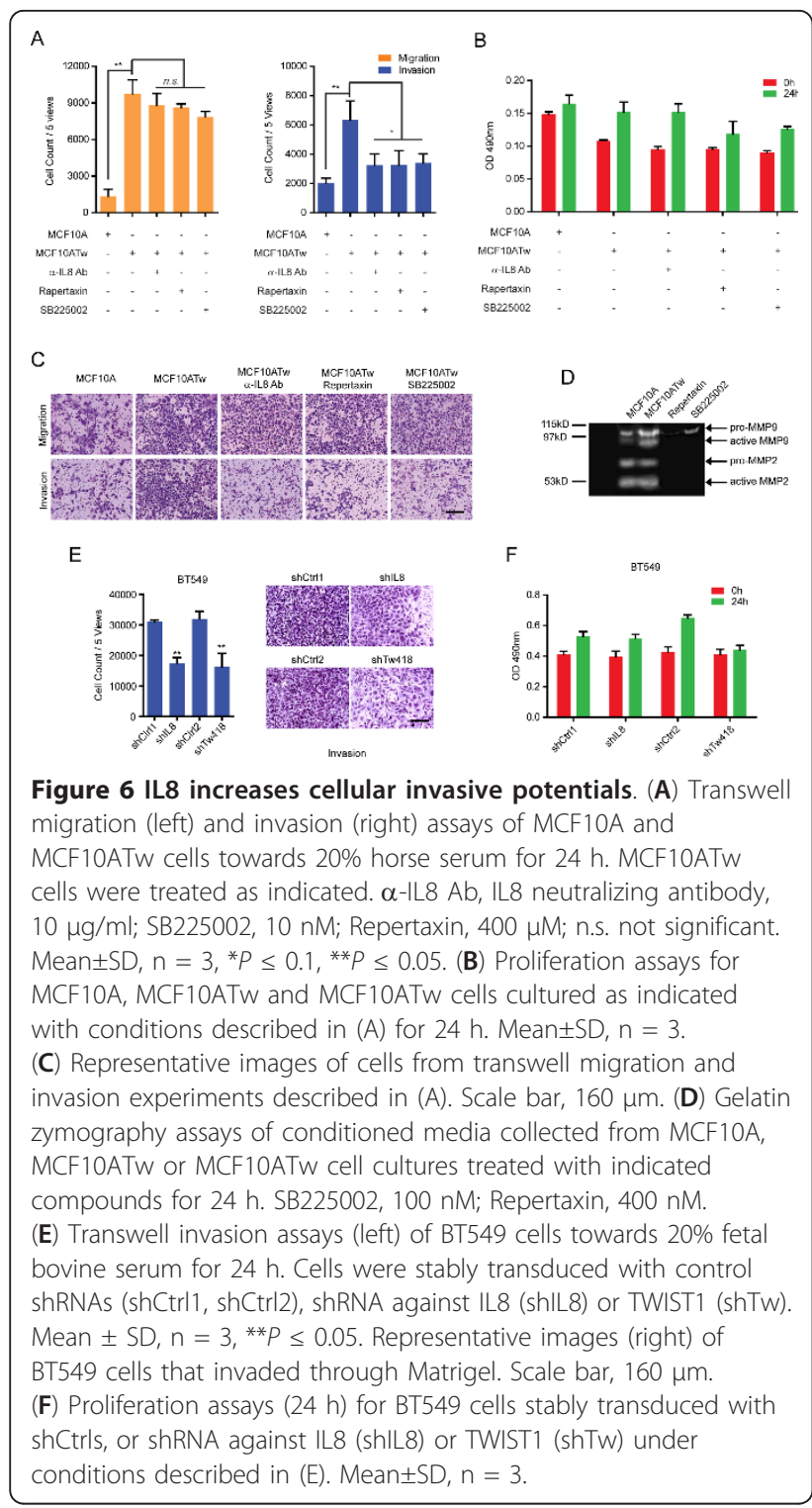

non-basal breast cancer cell lines (Figure 7A). Although the amounts of $I L 8$ transcript did not appear to be proportional to the detected levels of TWIST1, which is likely due to the presence of other IL8 regulators in these cell lines, these results indicate an overall correlation between TWIST1 and IL8 expression in the aggressive basal subtype of human breast cancers.

To determine the relevance of the in vitro mechanistic studies in relation to patient samples, we analyzed the relative expression levels of TWIST1 and IL8 in the STOCKHOLM (GSE1456) and UPPSALA (GSE3494) human breast tumor datasets (with a total of 412 samples from both datasets combined). These samples were divided into
A

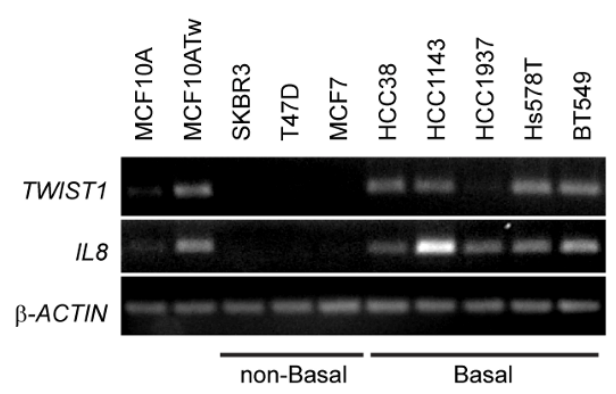

B
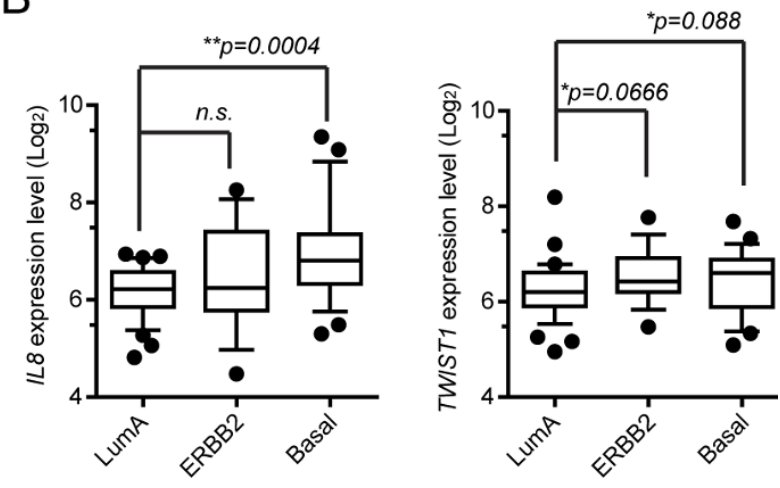

LumA $=39$, ERBB2 $=15$, Basal $=2$
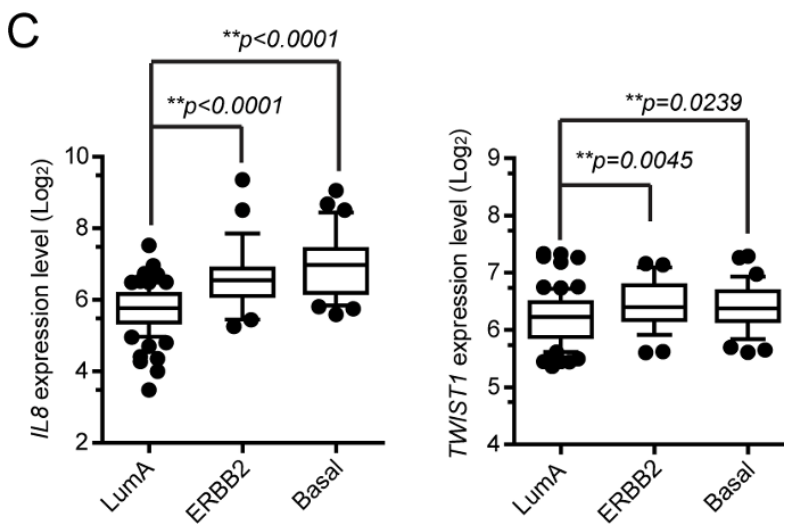

LumA $=82, E R B B 2=28$ Basal $=34$

Figure 7 TWIST1 and IL8 expression is enriched in the basal subtype of human breast cancers. (A) Reverse-transcription PCR of indicated cell lines for TWIST1 and IL8 with $\beta$-ACTIN as control. (B) Relative mRNA levels of IL8 and TWIST1 of luminal A (LumA), ERBB2/HER2+ (ERBB2) and basal subtypes from STOCKHOLM human breast tumor dataset (total $n=159$ ). Boxes represent the lower quartile, median and upper quartile; Whiskers represent the tenth and ninetieth percentiles; and dots represent outliers. $P$-values were calculated using Mann-Whitney $U$ test. (C) Relative mRNA levels of IL8 and TWIST1 of LUMA, ERBB2 and basal subtypes from UPPSALA human breast tumor dataset (total $n=253$ ). Graphs were plotted and $P$-values calculated as described in (B). 
luminal A, luminal B, normal-like, ERBB2 and basal subtypes based on their molecular intrinsic signatures identified by Calza et al. ([33], personal communication with Dr. Pawitan). Results from these analyses demonstrate significantly higher levels of IL8 expression in the basal compared to the luminal A subtype in both datasets, which was also seen in the ERBB2 subtype in the UPPSALA dataset (Figure 7B, C). Moreover, although the overall differences in relative expression levels of TWIST1 were small across different subtypes, TWIST1 expression was significantly elevated in the basal as well as the ERBB2 subtypes in both datasets when compared to luminal A subtype (Figure 7B, C). More importantly, the co-expression of TWIST1 and IL8 is correlated in the basal and ERBB2 subtypes, the two most aggressive subtypes of human breast cancers [33], supporting the important roles of the transcription factor and the cytokine in the pathology of advanced breast cancers.

\section{Discussion}

Herein, we show that TWIST1 up-regulates IL8 expression to induce cell autonomous invasion through the conserved C-terminal WR domain. The WR domain mediates the association of TWIST1 and RELA, which is essential for TWIST1-induced stimulation and synergism of NF- $\kappa \mathrm{B}$ transcriptional activity and IL 8 production. Additionally, TWIST1 forms a protein complex with RELA and enhances the association of RELA with the IL8 promoter, thus inducing IL8 expression. Finally, TWIST1-mediated secretion of IL8 establishes an autocrine loop in breast cells to regulate MMP production and cell invasion.

TWIST1 is commonly characterized by its bHLH domain, which is thought to be responsible for the transcriptionally regulated events controlled by this molecule [2,10,14-16]. However, the functional domains of TWIST1 have not been thoroughly studied and many questions are unanswered regarding their potential interacting partners, which in turn can be highly valuable for understanding the mechanism of cancer cell dissemination. Here we demonstrate that instead of direct IL8 gene activation, TWIST1 interacts with RELA, a non-HLH binding partner, and activates/synergizes transcriptional activity of NF- $\kappa \mathrm{B}$ to up-regulate the NF- $\kappa \mathrm{B}$ downstream gene target, IL8, which in turn regulates MMP production and cell invasion. This example indicates that TWIST1 can recruit non-HLH transcription factors to form protein complexes and modify gene expression downstream of this partner, which is supported by previous developmental and biochemical studies showing that TWIST1 can regulate the activity of its interacting co-factors [21,34,35].

RELA is a subunit of the NF- $\kappa \mathrm{B}$ complex, which is a central mediator of inflammatory responses [36] and causes many pathophysiological conditions upon activation [37], including tumorigenesis and metastasis $[38,39]$. Previous reports indicated that during normal mesodermal tissue development, TWIST1 and 2 inhibited the transcriptional activity of NF- $\kappa \mathrm{B}$ and suppressed expression of the pro-inflammatory cytokines TNF- $\alpha$ and IL-1 $\beta$ [26]. In contrast, our results show that in breast tumor cell lines, TWIST1 stimulates NF- $\kappa \mathrm{B}$ through the TWIST1 WR domain and up-regulates the expression of the NF- $\kappa \mathrm{B}$ downstream target gene IL8. These findings are in agreement with an earlier report indicating that TWIST1 synergizes the transcriptional activity of NF- $\kappa \mathrm{B}$ in a manner that is independent of its bHLH domain [28]. The seemingly contradicting data in normal mesodermal tissues and breast tumor cell lines may indicate there are additional players modifying the functional relationships between TWIST1 and RELA during different processes in development. We hypothesize that the potential regulatory mechanisms may involve the initial availability of additional co-factors in a given cell type as well as the transcription factor binding sites present on specific target promoters. As an example, during dorsal-ventral development in Drosophila embryos, the cell types along the lateral wall of the embryo are determined by the expression of genes $[40,41]$, which are differentially regulated by gradients of the morphogens Dorsal (orthologue of RELA) and Twist, as well as the proximity of the binding sites on promoters of these genes [42]. Here, the selective induction of IL8 among many cytokines also argues for the importance of promoter organization as a critical factor that determines gene regulation by TWIST1 and NF- $\kappa \mathrm{B}$ as in comparison to a non-cytokine NF- $\kappa \mathrm{B}$ target gene, $\mathrm{I} \kappa \mathrm{B} \alpha$, whose promoter was not enriched with either TWIST1 or RELA in our ChIP assays (data not shown).

Our data that TWIST1 activates RELA to induce IL8 expression suggest that in breast epithelial and cancer cells, the expression of TWIST1 can translate an extracellular signal, such as hypoxia, and signal intracellularly to modify the activity of endogenous RELA and induce IL8 expression specifically when there is no apparent extracellular signal for NF- $\kappa \mathrm{B}$ activation. Furthermore, that TWIST1 can synergize the IL8 promoter activation induced by TNF- $\alpha$ indicates that TWIST1- and TNF- $\alpha$ induced RELA/NF- $\kappa \mathrm{B}$ activation contain overlapping yet non-identical biological effects. Finally, Pham et al. [43] confirm Sosic et al.'s findings [26] that TWIST1 is a downstream target of RELA, yet they found that TWIST1 acts as a RELA effector protein to block programmed cell death mediated by TNF- $\alpha$ treatment, implying that the functional relationships between TWIST 1 and TNF- $\alpha$ in NF- $\kappa$ B activation can depend on the genes being regulated and the physiological conditions of the specific cell type. 
Despite some discrepancies [44], IL8 expression was elevated in both invasive cancer cells $[45,46]$ and in the sera of patients with aggressive cancers $[47,48]$. It is well known that IL8 induces potent neutrophil chemotaxis [49], which causes cytoskeletal reorganization, as well as release and activation of MMPs from neutrophils to induce directed migration of the granulocytes [50]. Here we show that TWIST1-induced IL8 expression in breast epithelial cells up-regulates MMP production and enhances cellular invasive property without affecting migratory ability, suggesting that the biological effects of IL8 on motivating cytoskeleton remodeling are slightly different in cancer cells. This also implies that secreted IL8 primarily enhances the cellular ability to degrade basement membrane (laminin, the primary component of Matrigel), a phenomenon common in metastatic cancers. Blockage of IL8 signaling or knockdown of the cytokine with shRNAs against TWIST1 did not cause MCF10ATw (Figure 6C, top panel) or BT549 (Figure $6 \mathrm{E}$, upper right) cells to lose their mesenchymal phenotype, indicating the reduced invasive properties resulted from IL8 signaling inhibition was not a result of reversion of EMT. This observation may be because of the fact that mesenchymal-epithelial transition is a lengthy process; however, immunoblots of epithelial and mesenchymal markers of BT549 cells stably transduced with shIL8 or shTw did not appear to be morphologically or biochemically different from the BT549.shCtrl cells (data not shown), suggesting the increased cellular invasiveness mediated by IL8 expression is independent of the EMT process.

The fact that IL8 is a chemokine for neutrophils is another important element for tumorigenesis and the development of tumor microenvironment. Neutrophils are short-lived multinuclear white blood cells that have a profound role in ECM degradation and are responsible for several diseases characterized by severe damage of tissue structure [51-53]. The expression of IL8 by tumor cells can cause infiltration of neutrophils (tumor-associated neutrophils, TAN), which has been evident for many years [54]. It was recently discovered that, like tumor-associated macrophages, TAN also displayed two phases of actions, switching from the anti-tumorigenic to the proto-tumorigenic stage [55], providing evidence of the involvement of neutrophils in cancer progression. Moreover, IL8 is a known effective pro-angiogenic factor [56] that promotes endothelial cell survival and MMP production critical for vascularization [30]. This characteristic of IL8 may partially be responsible for TWIST1-associated tumor angiogenesis that was previously noted by our group and collaborators in TWIST1 over-expressing MCF7 breast tumor cells [57]. Overall, increase of basal expression of IL8 can bring forth its pleiotropic effects in affecting tumor progression, remodeling of the tumor microenvironment and the formation of cancer metastasis.

\section{Conclusions}

Our study demonstrates that the TWIST1 WR domain is functionally critical to TWIST1-induced cell invasion. This domain is essential for the interaction between TWIST1 and the NF- $\kappa$ B subunit RELA, which is key to IL8 induction. TWIST1-mediated up-regulation of IL8 leads to MMP production and ECM degradation, resulting in enhanced cell-autonomous invasion.

\section{Methods}

\section{Cell culture and transfection}

The MCF10ATw cell line was generated by stable transfection [58] of pcDNA3-TWIST [59] into MCF10A cells (an immortalized normal human breast epithelial cell line, American Type Culture Collection, ATCC, Manassas, VA, USA). MCF10ATw and MCF10A cells were cultured as previously described [60]. HEK293, SKBR3, MCF7 and BT549 cell lines were purchased from ATCC and cultured using ATCC's recommended protocols and authentication methods. All cells were maintained at $37^{\circ} \mathrm{C}, 5 \% \mathrm{CO}_{2}, 90 \%$ humidity in a tissue culture (TC) incubator. Transfections were performed using Lipofectamine 2000 (Invitrogen, Carlsbad, CA, USA) according to the manufacturer's instructions.

\section{Microarray analysis}

Triplicate samples of MCF10A and MCF10ATw cells were used for expression profiling with the Affymetrix Human Genome U133 Plus 2.0 array, and data collection was performed in the Microarray Core Facility at City of Hope. RNA was extracted using TRIzol reagent (Invitrogen) and analyzed for integrity using an Agilent Bioanalyzer 2100 (Agilent Technologies, Wilmington, DE, USA). Double stranded cDNA was reverse transcribed using total RNA $(5 \mu \mathrm{g})$, the GeneChip ${ }^{\circledR}$ Expression 3'-Amplification Reagents One-Cycle cDNA Synthesis Kit (Affymetrix, Santa Clara, CA, USA) and oligo-dT primers containing a T7 RNA polymerase promoter. A 1:10 dilution of Poly-A controls $(2 \mu \mathrm{l})$ was added as an internal control for the synthesis. Double-stranded cDNA was used as a template to generate biotinylated cRNA using the GeneChip ${ }^{\circledR}$ Expression 3'-Amplification Reagents for in vitro transcription labeling (Affymetrix). Biotin-labeled cRNA was fragmented following the Affymetrix protocol. Hybridization cocktails contained $15 \mu \mathrm{g}$ fragmented cRNA, $5 \mu \mathrm{l} 3$ $\mathrm{nM}$ control oligonucleotide B2, $15 \mu \mathrm{l} 20 \mathrm{X}$ eukaryotic hybridization controls, BSA $(0.5 \mathrm{mg} / \mathrm{ml})$, herring sperm DNA (0.1 mg/ml), dimethyl sulfoxide (DMSO) (10\%), and hybridization buffer for a final volume of $300 \mu \mathrm{l}$. Hybridization cocktails $(200 \mu \mathrm{l})$ were hybridized $\left(45^{\circ} \mathrm{C}, 16 \mathrm{~h}\right)$ to 
HG U133 Plus 2.0 Affymetrix arrays in an Affymetrix GeneChip Hybridization Oven 640. GeneChip arrays were washed with wash buffer (Affymetrix, santa Clara, CA, USA) and stained with streptavidin-phycoerythrin on an Affymetrix Fluidics Station 450, followed by scanning on an Affymetrix GeneArray 3000 scanner. Data were extracted using GeneChip Operating Software (version 1.4) (Affymetrix, Santa Clara, CA USA). Analysis of microarray data was performed using Partek Genomics Suite 6.4 (Partek, Inc., St. Louis, MO, USA) as follows. The Robust Multi-array Average (RMA) algorithm was adapted to normalize and summarize the intensities of probes into genelevel expression. A two-way ANOVA model was used with TWIST over-expression and scan dates as factors to identify the effect contributed mainly by TWIST. Only genes with $P$-value $<0.05$ and |fold change $\mid>2$ were considered significantly differentially expressed. Genes were further analyzed using Gene Set enrichment Analysis (GSEA) to provide gene enrichment analysis and functional interpretation. A cytokine heat map was generated based on cytokine-related gene sets available from GSEA.

\section{ELISA}

Conditioned media from cell cultures with equal numbers of seeded cells $\left(8 \times 10^{5}\right.$, six-well plate) cultured for $24 \mathrm{~h}$ were collected for ELISA (eBiosciences, San Diego, CA, USA).

\section{Cytokine arrays, immunoblotting, and co-immunoprecipitations}

Cytokine arrays (RayBiotech, Inc., Norcross, GA, USA) were blotted using the manufacturer's instructions. For immunoblotting, proteins were resolved by SDS-PAGE and probed with anti-E-Cad (Cell Signaling, Danvers, MA, USA), anti-N-Cad (Abcam, San Francisco, CA, USA), antiVimentin (R\&D Systems, Minneapolis, MN, USA), antiTWIST1 (Abcam), anti-RELA (Santa Cruz Biotechnology Inc., Santa Cruz, CA, USA), anti-Myc (EMD, San Diego, CA, USA) and anti- $\beta$-actin (Sigma-Aldrich, St. Louis, MO, USA) antibodies. For immunoprecipitation, HEK293 cells were solubilized in RIPA buffer, the lysate centrifuged $(10,000 \times g, 10$ minutes $)$ and the supernatant containing the soluble proteins collected. Protein lysates $(100 \mu \mathrm{g})$ were first pre-cleared with normal IgG and protein A/G plus conjugated agarose beads (Santa Cruz Biotechnology, Inc.), then incubated with new beads and antibodies of interest overnight $\left(4^{\circ} \mathrm{C}\right.$, on a rocker). Beads were washed five times (RIPA buffer) and boiled in Laemmli loading buffer in the presence of Dithiothreitol for further analysis. BT549 cells collected for fractionation-coupled co-IP were first resuspended in $\mathrm{KCl}(10 \mathrm{mM})$ hypotonic buffer and lysed with $0.4 \%$ IGEPAL (NP-40 substitute); nuclei were collected by centrifugation and solubilized with high salt buffer $(0.4 \mathrm{M} \mathrm{NaCl})$ by rocking $\left(4^{\circ} \mathrm{C}, 1 \mathrm{~h}\right)$. Nuclear lysates were cleared by centrifugation $(16,000 \times g, 5$ minutes $)$ and the salt concentration was adjusted to $135 \mathrm{mM}$ for co-IP experiments.

\section{RT-PCR and quantitative PCR}

Total RNA was isolated with the RNeasy Mini Kit (Qiagen, Valencia, CA, USA). First strand cDNA was synthesized from $1 \mu \mathrm{g}$ total RNA with the iScript cDNA synthesis kit (Bio-Rad, Hercules, CA, USA). PCR was performed for 35 cycles $\left(95^{\circ} \mathrm{C}, 30 \mathrm{~s} ; 57^{\circ} \mathrm{C}, 30 \mathrm{~s} ; 72^{\circ} \mathrm{C}, 15 \mathrm{~s}\right)$ with Taq DNA polymerase (Invitrogen). Relative mRNA levels were quantified using SYBR supermix (Bio-Rad, Hercules, CA, USA) on an iCycler iQ5 for 40 cycles $\left(95^{\circ} \mathrm{C}\right.$, $\left.30 \mathrm{~s} ; 57^{\circ} \mathrm{C}, 15 \mathrm{~s} ; 72^{\circ} \mathrm{C}, 15 \mathrm{~s}\right)$ followed by default melting curve cycles and analyzed using IQ5 software by PCR baseline subtraction (Bio-Rad). The following primers were used: TWIST1 forward 5'-AGCAAGATTCAGACCCTCAAGC-3', reverse 5'-CTCCATCCTCCAGACCGAGA-3'; IL8 forward 5'-CTGTCTGGACCCC AAGGAAAACT-3', reverse 5'-GCAACCCTACAACAGACCCACAC-3'; $\beta$-ACTIN forward: 5'-CCGCAAAGACCTGTACGCCAAC-3', reverse 5'-CCAGGGCAGTG ATCTCCTTCTG-3'.

\section{Plasmids, shRNA constructs and viral production}

The human IL8 promoter (bases -262 to -55) was amplified from MCF10A genomic DNA (DNeasy ${ }^{\circledR}$ tissue kit, Qiagen) and cloned into pGL3 plasmid. pGL3-IL8 $\Delta \kappa \mathrm{B}$ and $\triangle \mathrm{E}$-box were generated by PCR site-directed mutagenesis (SDT). The coding sequences of TWIST1 full length and truncated (missing the last 20 amino acids, $\triangle$ WR) were amplified from pcDNA3-Tw [59] and subcloned into pcDNA4. SDT were induced to generate the C432A A433G mutations (S144R K145E) and C352T mutation (R118C). WT pcDNA4-TWIST1 was subcloned into pENTR4 (Invitrogen) to shuttle into pAd/ CMV/V5-DEST (Invitrogen) by LR clonase II (Invitrogen). Adenoviral particles were packaged using HEK293A cells, according to the manufacturer's guidelines, and titrated. The mRNA target sequences of shRNAs shTw1 (shTw) and shTw2 were 5'-GGACAAGCUGAGCAAGAUU-3' and 5'-GCGACGAGCUGGA CTCCAA-3', respectively. The sequences of shCtrl (mRNA target sequence UUCUCCGAACGUGUCAC GU) and shIL8 (mRNA target sequence GCCAAGGAGUGCUAAAGAA) were previously reported [61]. shRNAs were created with siRNA sequences connected to a loop and a complementary sequence that were cloned into pcDNA3-U6 (gift from Dr. John Rossi, Beckman Research Institute of City of Hope). The U6-shRNA fragments were subcloned into pENTR4 (Invitrogen) to shuttle into pLenti6/Block-It ${ }^{\mathrm{TM}}$-DEST (Invitrogen). Lentiviral particles were generated, according to the manufacturer's guidelines, using HEK293FT 
cells. pGL3-3X $\kappa \mathrm{B}, \mathrm{pCMV}-\mathrm{I} \kappa \mathrm{BSR}$, pPCR-shGFP and pPCR-shRelA plasmids were gifts from Dr. Rama Natarajan (Beckman Research Institute of City of Hope).

\section{Luciferase assays}

Cells were seeded in 24-well plates and co-transfected with pGL3 firefly luciferase promoter construct, pSV40-Renilla luciferase (Promega, San Luis Obispo, CA, USA) and transcription factor constructs of interest. After transfection (24 h), cell lysates were collected and firefly/renilla luciferase activities were assayed for luminescence using the Dual-Luciferase Reporter Assay System (Promega).

\section{Chromatin immunoprecipitation assay}

ChIP assays were performed using the fast ChIP protocol [62] with minor modifications as follows. Cells were crosslinked on a dish with $1.1 \%$ formaldehyde (10 minutes, room temperature), quenched with $1.25 \mathrm{M}$ glycine solution (5 minutes, room temperature), and collected in $1 \mathrm{ml}$ PBS with protease inhibitors cocktail (Roche Applied Science Indianapolis, IN, USA)). Cells were then processed and IPs performed as described [62]. Precipitated chromatin was quantified using quantitative PCR and presented as percent of input. Anti-TWIST1 antibodies used for ChIP were custom-made to target the sequence GCQPPSGKRGGRKRRTSRRT. Anti-RELA antibodies were from Santa Cruz Biotechnology, Inc.; normal rabbit IgG was from Millipore (Temecula, CA, USA). Enrichment of IL8 promoter was analyzed by qPCR and presented by percent input using primers forward 5'-GTGAT GACTCAGGTTTGCCC-3' and reverse 5'-GGTTGGT TTCTTCCTGGCTCT-3'. Control primers, forward 5'ATCAGTCAAGCCAGGTTGTGTC-3', reverse 5'-AACACAGTGCATGGAGTGACAA-3', target a region $2 \mathrm{~kb}$ upstream of the transcription initiation site for the IL8 gene.

\section{Transwell migration/invasion assays}

Transwell inserts (Millipore, $8 \mu \mathrm{m}$ pore diameter) were pre-coated with $1 \mathrm{mg} / \mathrm{ml}$ fibronectin and equilibrated with serum free medium in a TC incubator for $1 \mathrm{~h}$ Cells $(3.75$ $\times 10^{5}$ for MCF10A and MCF10ATw cells, $1 \times 10^{5}$ for BT549 cells) were resuspended in culture medium supplemented with $0.25 \%$ serum $(400 \mu \mathrm{l})$ and loaded onto the upper well of inserts. Media $(600 \mu \mathrm{l})$ that contained $20 \%$ serum and indicated components of interest were added to the lower well. For invasion assays, Matrigel $(60 \mu \mathrm{l}$, $3 \mathrm{mg} / \mathrm{ml}$, diluted with serum-free medium, BD Biosciences San Jose, California, USA) was layered on the upper membrane and placed in the TC incubator for 30 minutes to solidify. Cells were allowed to migrate/invade for $24 \mathrm{~h}$, followed by fixation with $4 \%$ paraformaldehye and staining with hematoxilin and eosin. Transwell membranes were removed and cells on the upper side cleaned off with a cotton tip. Membranes were then mounted and images taken of the upper, lower, left, right and center of the membrane. Migrated or invaded cells were quantified using Image-ProPlus5.1 (Media Cybernetics, Inc. Rockville, MD 20850 USA). and data presented as a sum of the five images. Neutralizing anti-IL8 antibodies were purchased from R\&D Systems; IL8 inhibitors repertaxin and SB225002 were from Sigma.

\section{Proliferation assays}

Cells $\left(3.75 \times 10^{4}\right.$ for MCF10A and MCF10ATw cells; $10^{4}$ for BT549 cells) were seeded in 96 -well plates in equivalent conditions as for migration/invasion assays, and cell counts were determined with CellTiter $96 \mathrm{Aqu}-$ eous One solution (Promega) according to the manufacturer's guidelines.

\section{Gelatin zymography}

Conditioned media collected from MCF10A and MCF0ATw cells were filtered through a PVDF $0.45 \mu \mathrm{m}$ low protein binding filter, concentrated using a 3000 NMWL Centricon concentrator (Millipore), mixed with $\beta$-mercaptoethanol-free loading buffer and resolved on a non-reducing PAGE gel that contained $0.1 \%(1 \mathrm{mg} / \mathrm{ml})$ gelatin (Sigma). The gel was then incubated $(1 \mathrm{~h}$, room temperature, with shaking) in $2.5 \%$ Triton-X100 solution in water, followed by incubation (overnight, $37^{\circ} \mathrm{C}$ ) in digestion buffer (10 $\mathrm{mM}$ calcium chloride, $20 \mathrm{mM}$ Tris Acetic Acid, $\mathrm{pH}$ of 7.5). The gelatin gel was then stained with Coomassie Brilliant Blue (Bio-Rad) for 30 minutes at room temperature, washed with destaining solution (50:10:40 methanol:acetic acid:water) and imaged using a Kodak Electrophoresis Documentation and Analysis System 290 Eastman Kodak Company, Molecular Imaging Systems, New York, USA.

\section{Bioinformatics and statistical analysis}

STOCKHOLM (GSE1456) and UPPSALA (GSE3494) microarray data sets were downloaded from the NCBI Gene Expression Omnibus. The data were divided into subtypes [33] based on information provided by Dr. Yudi Pawitan (Karolinska Institut, Sweden) and relative expression levels were represented by raw data. Nonparametric Mann-Whitney U test was performed to calculate the $P$-values presented.

\section{Additional material}

\footnotetext{
Additional file 1: Figure S1. Cytokine pathway was enriched in MCF10ATw relative to MCF10A cells. (A) Enrichment plot of changes in mRNA levels of cytokines included in the Biocarta_Cytokine_Pathway in MCF10ATw versus MCF10A cells. Profile of the running ES Score and positions of gene set members on the ranked list of genes are shown. (B) Heat map of cytokine expression in MCF10ATw versus MCF10A cells. Microarray data were performed in triplicate. Each row represents relative
} 
expression levels of a gene and each column represents one replicate of MCF10A or MCF10ATw cells. Red and blue indicate up-regulated or down-regulated expression, respectively. (C) Relative mRNA levels normalized to $\beta$-ACTIN (left) (See Methods) and secreted IL8 per $8 \times 10^{5}$ cells (right) from MCF10A and MCF10ATw cells. (D) Details of the GSEA analysis for the Biocarta_Cytokine_Pathway.

Additional file 2: Table S1. Cytokine Array Map.

Additional file 3: Figure S2. IL8 promoter activation is independent of mutations in the TWIST1 bHLH DNA binding domain. (A) Relative luciferase activities of SKBR3, MCF7 or BT549 cells $24 \mathrm{~h}$ post-transfection with IL8 WT or $\triangle \mathrm{E}$-box mutant promoter constructs together with TWIST1 or pcDNA vector control. WT, WT IL8 promoter; $\triangle \mathrm{E}$-box, $\triangle \mathrm{E}$-Box IL8 mutant promoter. (B) Relative luciferase activities of SKBR3 and MCF7 cells co-transfected with IL8 promoter reporter plasmid and WT, R118C $\triangle W R$, S144R K145E $\triangle W R$ or $\triangle \mathrm{bHLH}$ (complete removal of the bHLH domain) mutant TWIST1. (C) Western blot of nuclear TWIST1 in SKBR3 and MCF7 cells that were transfected with or without TWIST1 and/or I $\kappa$ BSR. (D) Relative luciferase activities of IL8 promoter in BT549 cells stably transduced with shRNAs against TWIST1 and transiently transfected with either shGFP or shRelA ( $24 \mathrm{~h}$ ). In $A, B, D$, data shown are from single representative experiments. Mean $\pm \mathrm{SD}, \mathrm{n}=3,{ }^{*} P \leq 0.05,{ }^{*} P \leq 0.01$. (E) Western blot of cytoplasmic and nuclear RELA in MCF10A and MCF10ATw cells. Cyto., cytoplasmic; nu., nuclear. (F) Immunoprecipitation of nuclear RELA in HEK293 cells that were transfected with indicated constructs. Normal rabbit lgG was used as controls. (G) ChIP assays using $\alpha$-TWIST1 antibodies with solublized chromatin collected from HEK293 cells transfected with vector control, TWIST1, or TWIST1 and RELA for $48 \mathrm{~h}$

\section{Abbreviations}

bHLH: Basic helix-loop-helix; ChIP: chromatin immunoprecipitation; Co-IP: coimmunoprecipitation; EMT: epithelial-mesenchymal Transition; ECM: extracellular matrix; GSEA: Gene Set Enrichment Analysis; IL8: Interleukin 8; KD: knock-down; MMP: matrix metalloproteinase; NF-KB: Nuclear Factorkappa B; SCS: Saethre-Chotzen Syndrome; shRNA: short hairpin RNA; TNF-a: Tumor Necrosis Factor alpha; WT: wild type

\section{Acknowledgements}

This project was supported by grant number R21 CA107245 to CAG and grant number P30 CA033572 from the National Cancer Institute. Its contents are solely the responsibility of the authors and do not necessarily represent the official views of the National Cancer Institute or NIH. Additional support was provided by the Rosalind and Arthur Gilbert Foundation, the Jewish Federation of Los Angeles, the Pacific Northwest Foundation and the AVON Breast Cancer Foundation.

We thank Drs. Guihua Sun and Lisa Scherer from Dr. John Rossi's laboratory (City of Hope, Beckman Research Institute) for their help in the design of shRNA against TWIST1 and providing the pCDNA3-U6 plasmid vector used in this study. We also thank Dr. Yudi Pawitan (Karolinska Institutet, Sweden) for providing information on the human breast tumor datasets; Dr. Rama Natarajan and her group (City of Hope, Beckman Research Institute) for helpful discussions and technical support; and Dr. Keely Walker (City of Hope, Beckman Research Institute) for her critical and thorough editorial review during the preparation of this manuscript.

\section{Author details}

'Division of Neurosciences, Beckman Research Institute of the City of Hope, Duarte, CA 91010, USA. ${ }^{2}$ Department of Neurosurgery, Beckman Research Institute of the City of Hope, Duarte, CA 91010, USA. '3 Department of Molecular Medicine, Beckman Research Institute of the City of Hope, Duarte, CA 91010, USA. ${ }^{4}$ Irell \& Manella Graduate School of Biological Sciences, Beckman Research Institute of the City of Hope, Duarte, CA 91010, USA. ${ }^{5}$ Department of Biological Sciences, California State Polytechnic Institute, Pomona, CA 91768, USA. ${ }^{6}$ GeneTex, Irvine, CA 92606, USA. ${ }^{7}$ Affymetrix, Santa Clara, CA 95051, USA. ${ }^{8}$ Western University of Health Sciences, Pomona, CA 91766, USA. 'University of California Berkeley, Berkeley, CA 94720, USA.

${ }^{10}$ StemCell Technologies Inc., Vancouver, BC V5Z 1B3, Canada.

\section{Authors' contributions}

SL carried out the molecular and cellular studies, participated in the experimental design and data analysis, and drafted the manuscript. SEK conceived of the study and carried out the cytokine array immunoblots. RR participated in the ChIP assays. JF carried out part of the ChIP assays. MC carried out the microarray study. ZL carried out the GSEA analysis and participated in the statistical analysis. GL participated in the GPCR and luciferase reporter assays. YHL, YHT, VL and SD participated in plasmid construction. SF participated in the microarray study and analysis. KSA participated in the initial design and coordination of this study and reviewed the manuscript. CG participated in conceiving of the study, its design and coordination, and helped to draft the manuscript. All authors read and approved the final manuscript.

\section{Competing interests}

The authors declare that they have no competing interests.

Received: 10 February 2012 Accepted: 14 August 2012 Published: 14 August 2012

\section{References}

1. Sporn MB: The war on cancer. The Lancet 1996, 347:1377-1381.

2. Yang J, Mani SA, Donaher JL, Ramaswamy S, Itzykson RA, Come C, Savagner P, Gitelman I, Richardson A, Weinberg RA: Twist, a master regulator of morphogenesis, plays an essential role in tumor metastasis. Cell 2004, 117:927-939.

3. Kwok WK, Ling MT, Lee TW, Lau TC, Zhou C, Zhang X, Chua CW, Chan KW, Chan FL, Glackin C, Wong YC, Wang X: Up-regulation of TWIST in prostate cancer and its implication as a therapeutic target. Cancer Res 2005, 65:5153-5162.

4. Kajiyama H, Hosono S, Terauchi M, Shibata K, Ino K, Yamamoto E, Nomura S, Nawa A, Kikkawa F: Twist expression predicts poor clinical outcome of patients with clear cell carcinoma of the ovary. Oncology 2006, 71:394-401.

5. Ou DL, Chien HF, Chen CL, Lin TC, Lin LI: Role of Twist in head and neck carcinoma with lymph node metastasis. Anticancer Res 2008, 28:1355-1359.

6. Matsuo N, Shiraha H, Fujikawa T, Takaoka N, Ueda N, Tanaka S, Nishina S, Nakanishi Y, Uemura M, Takaki A, Nakamura S, Kobayashi Y, Nouso K, Yagi T, Yamamoto $\mathrm{K}$ : Twist expression promotes migration and invasion in hepatocellular carcinoma. BMC Cancer 2009, 9:240.

7. Ru GQ, Wang HJ, Xu WJ, Zhao ZS: Upregulation of Twist in Gastric Carcinoma Associated with Tumor Invasion and Poor Prognosis. Pathology Oncology Research 2010, 1-7.

8. Chen ZF, Behringer RR: twist is required in head mesenchyme for cranial neural tube morphogenesis. Genes Dev 1995, 9:686-699.

9. Gitelman I: Twist protein in mouse embryogenesis. Dev Biol 1997, 189:205-214

10. Vesuna $F$, van Diest $P$, Chen $J H$, Raman V: Twist is a transcriptional repressor of E-cadherin gene expression in breast cancer. Biochemical and Biophysical Research Communications 2008, 367:235-241.

11. Casas E, Kim J, Bendesky A, Ohno-Machado L, Wolfe CJ, Yang J: Snail2 is an essential mediator of Twist1-induced epithelial mesenchymal transition and metastasis. Cancer Res 2011, 71:245-254.

12. Kalluri R: EMT: when epithelial cells decide to become mesenchymal-like cells. J Clin Invest 2009, 119:1417-1419.

13. Chaffer $\mathrm{CL}$, Weinberg RA: A perspective on cancer cell metastasis. Science 2011, 331:1559-1564.

14. Cheng GZ, Chan J, Wang Q, Zhang W, Sun CD, Wang L-H: Twist Transcriptionally Up-regulates AKT2 in Breast Cancer Cells Leading to Increased Migration, Invasion, and Resistance to Paclitaxel. Cancer research 2007, 67:1979-1987.

15. Ma L, Teruya-Feldstein J, Weinberg RA: Tumour invasion and metastasis initiated by microRNA-10b in breast cancer. Nature 2007, 449:682-688.

16. Eckert Mark A, Lwin Thinzar M, Chang Andrew T, Kim J, Danis E, OhnoMachado L, Yang J: Twist1-Induced Invadopodia Formation Promotes Tumor Metastasis. Cancer Cell 2011, 19:372-386.

17. Castanon I, Baylies MK: A Twist in fate: evolutionary comparison of Twist structure and function. Gene 2002, 287:11-22.

18. El Ghouzzi V, Legeai-Mallet L, Benoist-Lasselin C, Lajeunie E, Renier D, Munnich A, Bonaventure J: Mutations in the basic domain and the loop- 
helix II junction of TWIST abolish DNA binding in Saethre-Chotzen syndrome. FEBS Lett 2001, 492:112-118.

19. Gripp KW, Zackai EH, Stolle CA: Mutations in the human TWIST gene. Human Mutation 2000, 15:150-155.

20. Howard TD, Paznekas WA, Green ED, Chiang LC, Ma N, Ortiz de Luna RI, Garcia Delgado C, Gonzalez-Ramos M, Kline AD, Jabs EW: Mutations in TWIST, a basic helix-loop-helix transcription factor, in Saethre-Chotzen syndrome. Nat Genet 1997, 15:36-41.

21. Bialek P, Kern B, Yang X, Schrock M, Sosic D, Hong N, Wu H, Yu K Ornitz DM, Olson EN, Justice MJ, Karsenty G: A Twist Code Determines the Onset of Osteoblast Differentiation. Developmental Cell 2004, 6:423-435.

22. Subramanian A, Tamayo P, Mootha VK, Mukherjee S, Ebert BL, Gillette MA, Paulovich A, Pomeroy SL, Golub TR, Lander ES, Mesirov JP: Gene set enrichment analysis: a knowledge-based approach for interpreting genome-wide expression profiles. Proc Natl Acad Sci USA 2005, 102:15545-15550.

23. Liu M, Ju X, Willmarth NE, Casimiro MC, Ojeifo J, Sakamaki T, Katiyar S, Jiao X, Popov VM, Yu Z, Wu K, Joyce D, Wang C, Pestell RG: Nuclear factorkappaB enhances ErbB2-induced mammary tumorigenesis and neoangiogenesis in vivo. Am J Pathol 2009, 174:1910-1920.

24. Mukaida N, Mahe Y, Matsushima K: Cooperative interaction of nuclear factor-kappa B- and cis-regulatory enhancer binding protein-like factor binding elements in activating the interleukin-8 gene by proinflammatory cytokines. J Biol Chem 1990, 265:21128-21133.

25. Stein B, Baldwin AS Jr: Distinct mechanisms for regulation of the interleukin-8 gene involve synergism and cooperativity between C/EBP and NF-kappa B. Mol Cell Biol 1993, 13:7191-7198.

26. Sosic D, Richardson JA, Yu K, Ornitz DM, Olson EN: Twist regulates cytokine gene expression through a negative feedback loop that represses NF-kappaB activity. Cell 2003, 112:169-180.

27. Traenckner EB, Pahl HL, Henkel T, Schmidt KN, Wilk S, Baeuerle PA: Phosphorylation of human I kappa B-alpha on serines 32 and 36 controls I kappa B-alpha proteolysis and NF-kappa B activation in response to diverse stimuli. EMBO J 1995, 14:2876-2883.

28. Shirokawa JM, Courey AJ: A direct contact between the dorsal rel homology domain and Twist may mediate transcriptional synergy. Mol Cell Biol 1997, 17:3345-3355.

29. Chakrabarti S, Patel KD: Regulation of matrix metalloproteinase-9 release from IL-8-stimulated human neutrophils. J Leukoc Biol 2005, 78:279-288.

30. Li A, Dubey S, Varney ML, Dave BJ, Singh RK: IL-8 directly enhanced endothelial cell survival, proliferation, and matrix metalloproteinases production and regulated angiogenesis. J Immunol 2003, 170:3369-3376.

31. White JR, Lee JM, Young PR, Hertzberg RP, Jurewicz AJ, Chaikin MA, Widdowson K, Foley JJ, Martin LD, Griswold DE, Sarau HM: Identification of a potent, selective non-peptide CXCR2 antagonist that inhibits interleukin-8-induced neutrophil migration. J Biol Chem 1998, 273:10095-10098.

32. Casilli F, Bianchini A, Gloaguen I, Biordi L, Alesse E, Festuccia C, Cavalieri B, Strippoli R, Cervellera MN, Di Bitondo R, Ferretti E, Mainiero F, Bizzarri C, Colotta F, Bertini R: Inhibition of interleukin-8 (CXCL8/L-8) responses by repertaxin, a new inhibitor of the chemokine receptors CXCR1 and CXCR2. Biochem Pharmacol 2005, 69:385-394.

33. Calza S, Hall P, Auer G, Bjohle J, Klaar S, Kronenwett U, Liu ET, Miller L, Ploner A, Smeds J, Bergh J, Pawitan Y: Intrinsic molecular signature of breast cancer in a population-based cohort of 412 patients. Breast Cancer Res 2006, 8:R34.

34. Hamamori Y, Sartorelli V, Ogryzko V, Puri PL, Wu HY, Wang JY, Nakatani Y, Kedes $L$ : Regulation of histone acetyltransferases $p 300$ and PCAF by the bHLH protein twist and adenoviral oncoprotein E1A. Cell 1999, 96:405-413.

35. Hamamori Y, Wu HY, Sartorelli V, Kedes L: The basic domain of myogenic basic helix-loop-helix (bHLH) proteins is the novel target for direct inhibition by another bHLH protein, Twist. Mol Cell Biol 1997, 17:6563-6573.

36. Ghosh S, May MJ, Kopp EB: NF-kappa B and Rel proteins: evolutionarily conserved mediators of immune responses. Annu Rev Immunol 1998, 16:225-260.

37. Baker RG, Hayden MS, Ghosh S: NF-[kappa]B, Inflammation, and Metabolic Disease. Cell Metabolism 2011, 13:11-22.

38. Ben-Neriah Y, Karin M: Inflammation meets cancer, with NF-[kappa]B as the matchmaker. Nat Immunol 2011, 12:715-723.
39. Bollrath J, Greten FR: IKK/NF-[kappa]B and STAT3 pathways: central signalling hubs in inflammation-mediated tumour promotion and metastasis. EMBO Rep 2009, 10:1314-1319.

40. Jiang J, Kosman D, Ip YT, Levine M: The dorsal morphogen gradient regulates the mesoderm determinant twist in early Drosophila embryos. Genes \& Development 1991, 5:1881-1891

41. Ip YT, Park RE, Kosman D, Yazdanbakhsh K, Levine M: dorsal-twist interactions establish snail expression in the presumptive mesoderm of the Drosophila embryo. Genes Dev 1992, 6:1518-1530.

42. Szymanski P, Levine M: Multiple modes of dorsal-bHLH transcriptional synergy in the Drosophila embryo. EMBO J 1995, 14:2229-2238.

43. Pham CG, Bubici C, Zazzeroni F, Knabb JR, Papa S, Kuntzen C, Franzoso G: Upregulation of Twist-1 by NF-KB Blocks Cytotoxicity Induced by Chemotherapeutic Drugs. Molecular and Cellular Biology 2007, 27:3920-3935.

44. Derin D, Soydinc HO, Guney N, Tas F, Camlica H, Duranyildiz D, Yasasever V, Topuz E: Serum IL-8 and IL-12 levels in breast cancer. Med Oncol 2007, 24:163-168.

45. De Larco JE, Wuertz BR, Rosner KA, Erickson SA, Gamache DE, Manivel JC, Furcht LT: A potential role for interleukin-8 in the metastatic phenotype of breast carcinoma cells. Am J Pathol 2001, 158:639-646.

46. Green AR, Green VL, White MC, Speirs V: Expression of cytokine messenger RNA in normal and neoplastic human breast tissue: identification of interleukin- 8 as a potential regulatory factor in breast tumours. Int J Cancer 1997, 72:937-941.

47. Benoy IH, Salgado R, Van Dam P, Geboers K, Van Marck E, Scharpé S, Vermeulen PB, Dirix LY: Increased Serum Interleukin-8 in Patients with Early and Metastatic Breast Cancer Correlates with Early Dissemination and Survival. Clinical Cancer Research 2004, 10:7157-7162.

48. Orditura M, De Vita F, Catalano G, Infusino S, Lieto E, Martinelli E, Morgillo F, Castellano P, Pignatelli C, Galizia G: Elevated serum levels of interleukin-8 in advanced non-small cell lung cancer patients: relationship with prognosis. J Interferon Cytokine Res 2002, 22:1129-1135.

49. Waugh DJ, Wilson C: The interleukin-8 pathway in cancer. Clin Cancer Res 2008, 14:6735-6741.

50. Baggiolini M, Walz A, Kunkel SL: Neutrophil-activating peptide-1/ interleukin 8, a novel cytokine that activates neutrophils. J Clin Invest 1989, 84:1045-1049.

51. Hunninghake GW, Gadek JE, Lawley TJ, Crystal RG: Mechanisms of neutrophil accumulation in the lungs of patients with idiopathic pulmonary fibrosis. J Clin Invest 1981, 68:259-269.

52. Idell S, Kucich U, Fein A, Kueppers F, James HL, Walsh PN, Weinbaum G, Colman RW, Cohen AB: Neutrophil elastase-releasing factors in bronchoalveolar lavage from patients with adult respiratory distress syndrome. Am Rev Respir Dis 1985, 132:1098-1105.

53. Rola-Pleszczynski M, Gouin S, Begin R: Asbestos-induced lung inflammation. Role of local macrophage-derived chemotactic factors in accumulation of neutrophils in the lungs. Inflammation 1984, 8:53-62.

54. Schmidt KG, Rasmussen JW, Wedebye IM, Frederiksen PB, Pedersen NT: Accumulation of Indium-111-Labeled Granulocytes in Malignant Tumors. Journal of Nuclear Medicine 1988, 29:479-484.

55. Fridlender ZG, Sun J, Kim S, Kapoor V, Cheng G, Ling L, Worthen GS, Albelda SM: Polarization of tumor-associated neutrophil phenotype by TGF-beta: "N1" versus "N2" TAN. Cancer Cell 2009, 16:183-194.

56. Koch AE, Polverini PJ, Kunkel SL, Harlow LA, DiPietro LA, Elner VM, Elner SG, Strieter RM: Interleukin-8 as a macrophage-derived mediator of angiogenesis. Science 1992, 258:1798-1801.

57. Mironchik Y, Winnard PT, Vesuna F, Kato Y, Wildes F, Pathak AP, Kominsky $S$, Artemov D, Bhujwalla Z, Van Diest P, Burger H, Glackin C, Raman V: Twist Overexpression Induces In vivo Angiogenesis and Correlates with Chromosomal Instability in Breast Cancer. Cancer research 2005, 65:10801-10809.

58. Vesuna F, Lisok A, Kimble B, Raman V: Twist modulates breast cancer stem cells by transcriptional regulation of CD24 expression. Neoplasia 2009, 11:1318-1328.

59. Lee MS, Lowe GN, Strong DD, Wergedal JE, Glackin CA: TWIST, a basic helix-loop-helix transcription factor, can regulate the human osteogenic lineage. J Cell Biochem 1999, 75:566-577.

60. Debnath J, Muthuswamy SK, Brugge JS: Morphogenesis and oncogenesis of MCF-10A mammary epithelial acini grown in three-dimensional basement membrane cultures. Methods 2003, 30:256-268. 
61. Merritt WM, Lin $Y G$, Spannuth WA, Fletcher MS, Kamat AA, Han LY, Landen CN, Jennings N, De Geest K, Langley RR, Villares G, Sanguino A, Lutgendorf SK, Lopez-Berestein G, Bar-Eli MM, Sood AK: Effect of interleukin-8 gene silencing with liposome-encapsulated small interfering RNA on ovarian cancer cell growth. J Natl Cancer Inst 2008, 100:359-372.

62. Nelson JD, Denisenko O, Bomsztyk K: Protocol for the fast chromatin immunoprecipitation (ChIP) method. Nat Protoc 2006, 1:179-185.

doi:10.1186/1741-7007-10-73

Cite this article as: Li et al:: TWIST1 associates with NF- $\kappa B$ subunit RELA via carboxyl-terminal WR domain to promote cell autonomous invasion through IL8 production. BMC Biology 2012 10:73.

Submit your next manuscript to BioMed Central and take full advantage of:

- Convenient online submission

- Thorough peer review

- No space constraints or color figure charges

- Immediate publication on acceptance

- Inclusion in PubMed, CAS, Scopus and Google Scholar

- Research which is freely available for redistribution

Submit your manuscript at www.biomedcentral.com/submit 